\title{
Multidisciplinary Management of Elderly Cancer Patients: The Radiation Oncologist's Point of View
}

\author{
Dr. Antonio Stefanelli and Agostino Cristaudo* \\ Department of Radiation Oncology, University of Pisa, Italy
}

*Corresponding author: Agostino Aristaudo, Department of Radiation Oncology, University of Pisa, 56100 Pisa PI, Italy

\begin{abstract}
Oncological treatments of elderly patients are extremely complex; so far there's no agreement even on the definition of "geriatric patient". From the point of view of global health, the problem is of the outmost importance as the number of older patients will increase dramatically in the next years, leading to a change in world epidemiology with a significant increase of chronic-degenerative diseases such as cancer. For this reason, it's mandatory to provide clinical oncologists with multidisciplinary algorithms aiming at the best treatment of older cancer patients.
\end{abstract}

\section{Materials and Methods}

The complexity of oncological treatments for elderly patients starts from the very beginning, since the definition of "geriatric patient" is not univocal. From the point of view of public health, the problem is of the outmost importance. since nowadays there are 600 million people over 65 , in 10 years their number will overcome 1 billion and in 2050 there will be nearly half billion people over 80 [1-3]. Such an increase of longevity will lead to a change in world epidemiology with a significant increase of non-communicable disease such as cancer. In 2030 the annual incidence of new cases of cancer in aged people will be 13,7 million and, which is even more important, nearly half of such cases will be in low-income countries [4]. Very few clinical trials (which are the cornerstone of Oncology) take older patient into account, and usually they are very selected cases [5-8], quite differently from every day's practice, so there's paucity of data about care of older patients, which makes clinical oncologist's task even harder [5].Moreover, at least till few years ago, most guidelines and recommendations only consider chronological age in order to determinate the treatment's choice, and this policy has led to over- or under-treatments [5]. With the purpose of optimizing the treatment's choice it is imperative to focus on the concept of biological or functional age, in opposition to merely chronological age $[6,7]$.

We should briefly review the physiological modifications caused by aging, which affects every organ and apparatus. Considering for instance Nervous System, there is a decrease of cortical volume and of synaptic density, which leads to a weaker memory and attention.
Cardiovascular system is strongly affected, with a diminished cardiac output, increased arterial stiffness, slower modulation of cardiac frequency etc. [9]. Osteo-muscular apparatus is involved too, with a decrease of bone density leading to an increased risk of fracture and a sarchopenia which causes decreased physical activity with parallel increased fatigue and asthenia [10]. Additionally, for most of oncologic treatments, liver and kidney's function is crucial; with their reduction, drug toxicity increases. In some aged patients an aforementioned change is plain; in other they can be silent in conditions of balance, becoming evident in stress situations such as a malignant disease and its treatments [1].

\section{Biomolecular Markers of Aging}

Aging is an extremely complex phenomenon, showing deep differences among individuals, consequently so far, it's difficult to identify biological markers which enable us to divide subjects of the same chronological age into different functional ages. Several markers have been suggested, starting with markers of systemic inflammation such as CRP, D-dimer, IL 6 [8]. They are easily quantifiable, and they've been associated with functional decline in aged people, but their levels are influenced also by frankly pathological conditions like infections and cancer itself $[11,12]$. Markers of cellular aging have been considered too, such as telomeres or cell cycle components [8]. Dosing such markers is anyway extremely expensive, and moreover they have a significant interindividual variability. Another marker which could document a link between cancer and aging is P16 INK 4A, which has been 
showed to increase in aged breast cancer patients receiving chemotherapy [13]. Nevertheless, all of these markers are, so far, not completely validated and reliable.

\section{Geriatric Assessment}

As long as validated and reliable biomarkers are not established the best way to assess a geriatric cancer patient is clinical evaluation [14-17]. Geriatric assessment is a multidisciplinary and multi parametric evaluation which takes into account physical aspect, nutritional status, neurological and cognitive status and even social support $[18,19]$.

\section{Comorbidities}

When planning an oncological treatment at any age it's mandatory to take into account comorbidities. This is mainly true in aged patient, beginning from the commonest pathologies such as cardiovascular diseases, diabetes, chronic renal failure, collagenopathies [20].

\section{Polypharmacy}

About $50 \%$ of aged patients are on 5 or more different medical therapies before undertaking an oncologic treatment, so it's mandatory to evaluate all of these therapies and their potential interaction \interference with anticancer therapy [21].

\section{Nutritional Status}

Malnutrition and weight loss are deeply connected with cancer and its treatments and they have been shown to be linked to increased risk of toxicity and mortality [22].

\section{Functional Status}

All oncologists are familiar with ECOG and KPS scoring systems. In aged cancer patients it's appropriate to integrate them with other evaluation systems [5,8] such as ADL (Activities of Daily Living) and IADL (instrumental activities of daily living). For instance, an extremely simple and reliable indicator of functional status is the number of falls. They are seldom taken into account, but they seem to be connected with oncological treatments' toxicity.

\section{Cognitive Status}

The risk of cognitive decline increases with age. During anticancer treatment, it can cause for instance a diminished comprehension of its side effects which can be communicated with a delay, increasing the toxicity of the treatment itself, even in a serious way [1].

\section{Psychological Status}

Anxiety and depression worsen quality of life and precipitate functional decline, with a lower adherence to therapies [23].

\section{Social Support}

Many older people, so even aged cancer patients, live alone. It's been documented that social isolation is linked to a significant higher mortality in cancer patients [24].

\section{Screening Tools}

Many screening tools have been validated with the purpose of identifying aged cancer patients who can take advantage of a multidimensional geriatric assessment $[25,26]$. Among the commonest ones we mention G8 and Vulnerable Elderly Survey 13 [18]. The final result of these screening and of the subsequent geriatric evaluation is the final decision to perform an oncological treatment (and its intensity) or not [7]. Sometimes it could be appropriate not to perform a treatment with curative purpose in an aged patient because of multiple comorbidities (which could lead to increased toxicities and a reduction in life expectancy). In other circumstances, on the opposite side, it could be an error not to undertake a treatment only because of chronological age. Patient's preferences must be taken into account too; main international guidelines recommend to including patient in the therapeutic decision [27]. In this setting we must insert geriatric assessment; it's been documented in literature that multidimensional geriatric evaluation has lead to significant changes in treatment planning, in most of cases with the aim of attenuate it [28]. At the present a multidimensional geriatric assessment is not often performed in the process of decision making regarding oncologic treatment of older patients. It's been shown anyway that older cancer patients who have been evaluated in such a way have completed their treatment in a significant higher percentage, and with less modifications, compared to those who haven't received it.

\section{Radiotherapy}

radiotherapy is the clinical discipline which aims at curing cancer by means of ionizing radiations; it could be employed as the sole therapeutic modality or in association with surgery and \or systemic therapies. [29,30]. A geriatric evaluation is strongly advisable for older patients who are candidates to radiotherapy, first of all for those treatments which consider its association with a systemic therapy, but also for the exclusive setting. Around $70 \%$ of cancer patients will require a radiation treatment, and this is especially true in older patients, as state of art radiotherapy techniques offer higher cure rates with less side effects. Moreover, treatment time can be reduced, and this can help patient with logistic difficulties (e.g. distance from radiotherapy facility) and their family \caregivers. This is true first of all in the palliative setting (e. g. Treatment of pain from bone metastases), but it could be accomplished even in the non-palliative setting, with the adoption of shortest scheduled.

\section{Conclusion}

The first dilemma of radiation and medical oncologists treating aged patients is how to decide if a patient is suitable for a given treatment and whether to treat patients with standard protocols or with adapted regimens. So, it's advisable to include a geriatrician in multidisciplinary oncological teams (Tumour Board).

If it's not possible, a good result can be achieved even with a conventional geriatric evaluation and a higher cooperation among 
specialists. Anyway, even after an effective evaluation has declared that an older patient is fit enough to undergo an oncological treatment, it's mandatory to monitor such a patient in a closer and stricter way compared to a younger one [31].

\section{References}

1. Soto Perez de Celis E, Li D, Yuan Y, Lau YM, Hurria A (2018) Functional versus chronological age: geriatric assessments to guide decision making in older patients with cancer. Lancet Oncol 19(6): 305-316.

2. (2016) United States Census Bureau. International data base. Information Gateway.

3. UN (2015) Department of Economic and Social Affairs. Population Division. World population prospects, the 2015 revision.

4. Ferlay J SI, Ervik M, Dikshit R, et al. GLOBOCAN (2013) Cancer incidence and mortality worldwide: IARC Cancer Base 1: 11.

5. Antonio M, Saldaña J, Linares J, Ruffinelli JC, et al. (2018) Geriatric assessment may help decision- making in elderly patients with inoperable, locally advanced non-small-cell lung cancer. $\mathrm{Br}$ J Cancer 118(5):639-647.

6. Belgioia L, Desideri I, Errico A, Franzese C, Daidone A, et al. (2019) A Safety and efficacy of combined radiotherapy, immunotherapy and targeted agents in elderly patients: A literature review; AIRO Giovani Italian Association of Radiation Oncology-Young Members Working Group. Crit Rev Oncol Hematol 163-170.

7. Servagi Vernat S, Créhange G, Bonnetain F, Mertens C, Brain E, et al.(2017) Chemoradiation in elderly esophageal cancer patients: rationale and design of a phase I/II multicenter study (OSAGE) BMC Cancer 17(1): 483.

8. L Dumas, A Ring, J Butler, T Kalsi, D Harari, et al. (2016) Improving Outcomes for Older women with Gynaecological Malignancies. Cancer Treat Rev 50: 99-108.

9. North BJ, Sinclair DA (2012) The intersection between aging and cardiovascular disease. Circ Res 110(8): 1097-1098.

10. Arrieta H, Astrugue C, Regueme S, Durrieu J, Maillard A, et al. (2019) Effects of a physical activity programme to prevent physical performance decline in onco-geriatric patients: a randomized multicentre trial. J Cachexia Sarcopenia Muscle 10(2): 287-297.

11. Hubbard JM, Cohen HJ, Muss HB (2014) Incorporating biomarkers into cancer and aging research. J Clin Oncol 32: 2611-2616.

12. Sorrentino JA, Sanoff HK, Sharpless NE (2014) Defining the toxicology of aging. Trends Mol Med 20: 375-84.

13. Liu Y, Sanoff HK, Cho H, et al. (2009) Expression of p16INK4a in peripheral blood T-cells is a biomarker of human aging. Aging Cell 8: 439-448.

14. Balducci L, Beghe C (2000) The application of the principles of geriatrics to the management of the older person with cancer. Crit Rev Oncol Hematol 35: 147-154.

15. Solomon D, Sue Brown A, Brummel Smith K, Burgess L, DAgostino RB, et al. (2003) Best Paper of the 1980s: a^hNational Institutes of Health Consensus Development Conference Statement: Geriatric Assessment Methods for Clinical Decision-Making. J Am Geriatr Soc 51: 1490-1494.
16. Extermann M, Aapro M, Bernabei R, Cohen HJ, Droz JP, et al. (2005) Use of comprehensive geriatric assessment in older cancer patients: recommendations from the task force on CGA of the International Society of Geriatric Oncology (SIOG). Crit Rev Oncol Hematol 55(3): 241-252.

17. Handforth C, Clegg A, Young C, Simpkins S, Seymour MT, et al. (2014) The prevalence and outcomes of frailty in older cancer patients: a systematic review. Ann Oncol 26(6): 1091-1101.

18. Pottel L, Lycke M, Boterberg T, Pottel H, Goethals L, et al. (2015) G-8 indicates overall and quality-adjusted survival in older head and neck cancer patients treated with curative radio chemotherapy. BMC Cancer 15: 875 .

19. Balducci L (2009) Supportive care in elderly cancer patients. Curr Opin Oncol 21(4): 310-317.

20. Williams GR, Mackenzie A, Magnuson A, Olin R, Chapman A, et al. (2016) Comorbidity in older adults with cancer. J Geriatr Oncol 7(4): 249-257.

21. Maggiore RJ, Dale W, Gross CP, Feng T, Tew WP, etal. (2014) Polypharmacy and potentially inappropriate medication use in older adults with cancer undergoing chemotherapy: effect on chemotherapy-related toxicity and hospitalization during treatment. J Am Geriatr Soc 62(8): 1505-1512.

22. Magnuson A, Allore H, Cohen HJ, Mohile SG, Williams GR, et al. (2016) Geriatric assessment with management in cancer care: current evidence and potential mechanisms for future research. J Geriatr Oncol 7(4): 242248 .

23. Goodwin JS, Zhang DD, Ostir GV (2004) Effect of depression on diagnosis, treatment, and survival of older women with breast cancer. J Am Geriatr Soc 52(1): 106-111.

24. Caillet P, Canoui-Poitrine F, Vouriot J, Berle M, Reinald N, et al. (2011) Comprehensive geriatric assessment in the decision-making process in elderly patients with cancer: ELCAPA study. J Clin Oncol 29(27): 36363642.

25. Decoster L, Van Puyvelde K, Mohile S, Wedding U, Basso U, et al. (2015) Screening tools for multidimensional health problems warranting a geriatric assessment in older cancer patients: an update on SIOG recommendations. Ann Oncol 26(2): 288-300.

26. Decoster L, Van Puyvelde K, Mohile S, Wedding U, Basso U, et al. (2015) Screening tools for multidimensional health problems warranting a geriatric assessment in older cancer patients: an update on SIOG recommendationsw. Ann Oncol 26(2): 288-300.

27. (2016) National Comprehensive Cancer Network. Older Adult Oncology.

28. Hamaker ME, Schiphorst AH, ten Bokkel Huinink D, Schaar C, van Munster BC (2014) The effect of a geriatric evaluation on treatment decisions for older cancer patients-a systematic review. Acta Oncol 53(3): 289-296.

29. Delaney G, Jacob S, Featherstone C, Barton M (2005) The role of radiotherapy in cancer treatment: estimating optimal utilization from a review of evidence-based clinical guidelines. Cancer 104 (6): 11291137.

30. Hanna TP, Shafiq J, Delaney GP, Vinod SK, Thompson SR, et al. (2018) The population benefit of evidence-based radiotherapy: 5-Year local control and overall survival benefits. Radiother Oncol 126 (2): 191-197.

31. Daste A, Domblides C, Gross Goupil M, Chakiba C, Quivy A, et al. (2017) Immune checkpoint inhibitors and elderly people: a review. Eur J Cancer 82: $155-166$. 


\section{(c) \\ This work is licensed under Creative \\ Commons Attribution 4.0 License}

To Submit Your Article Click Here: Submit Article

DOI: $10.32474 /$ SCSOAJ.2019.03.000157

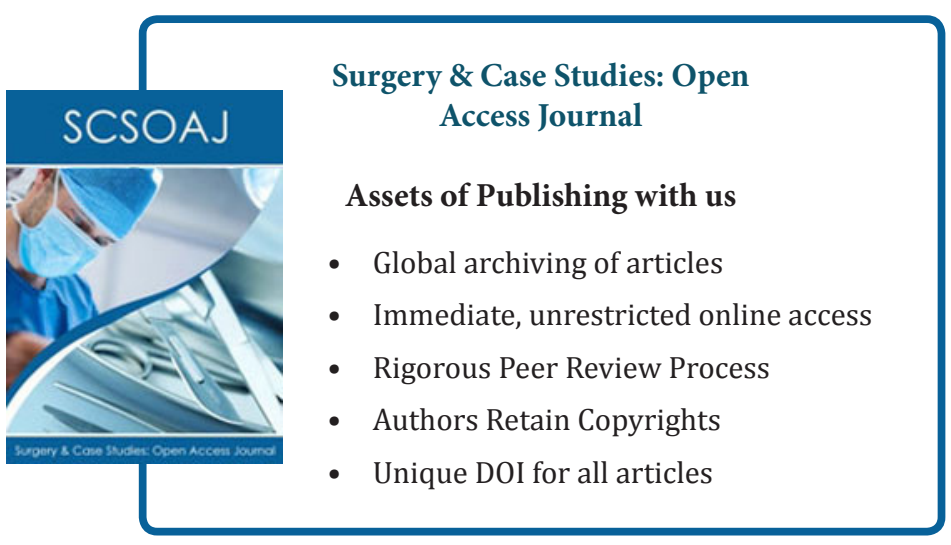

